\title{
CARACTERÍSTICAS QUALITATIVAS DE GENÓTIPOS DE CEBOLA
}

\author{
Qualitative characteristics of onion genotypes
}

\author{
Leilson Costa Grangeiro ${ }^{1}$, Jean de Oliveira Souza ${ }^{2}$, Edna Maria Mendes Aroucha ${ }^{3}$, \\ Glauber Henrique de Sousa Nunes ${ }^{4}$, Gilmara Mabel Santos ${ }^{5}$
}

\begin{abstract}
RESUMO
Objetivou-se, com o trabalho, avaliar alguns atributos de qualidade de diferentes genótipos de cebola (Allium cepa L.), cultivados em Mossoró-RN. O experimento foi realizado na horta experimental no Departamento de Ciências Vegetais da Universidade Federal Rural do Semi-Árido, em delineamento de blocos casualizados completos e quatro repetições. Os tratamentos foram constituídos pelos genótipos de cebola CNPH 6415, CNPH 6047, CNPH 6244, CNPH 6400 Chata, CNPH 6400 Redonda, CPACT 1, CPACT 2, CPACT 3, Granex 429, Belém IPA 9, BRS Cascata, Crioula Alto Vale, Bola Precoce, Primavera, Régia, Valeouro IPA-11, Brisa e Alfa São Francisco. As características avaliadas foram teor de sólidos solúveis totais, acidez total titulável, teor de vitamina $\mathrm{C}$ e teor de ácido pirúvico (pungência). Foram observadas diferenças significativas entre os genótipos para todas as características avaliadas. Os genótipos apresentaram uma variação significativa para todas as características avaliadas, confirmando dessa forma que o fator genético é determinante na caracterização de cada material. O teor de sólidos solúveis totais variou de 6,67 a 11,63 ( ${ }^{\circ}$ Brix), vitamina C de 22,7 a 46,81 (mg ácido ascórbico/100 ml de suco) e a acidez total titulável de 0,19 a 0,45 (\% de ácido pirúvico). Os genótipos apresentaram pungência intermediária com variação de 5,0 a 12,73 ( $\mu \mathrm{mol} / \mathrm{g})$, sendo os menos pungentes Granex 429, CNPH 6047, Régia, Primavera e Belém IPA 9.
\end{abstract}

Termos para indexação: Allium cepa, qualidade, pungência.

\section{ABSTRACT}

The aim of this work was to evaluate some attributes of quality of different genotypes of onion (Allium cepa L.), cultivated in Mossoró-RN. The experiment was carried out in the vegetable garden of Plant Science Department at Universidade Federal Rural do Semi-Árido. The experimental outline was of randomized complete blocks with four replications. The treatments were constituted by the genotypes of onion CNPH 6415, CNPH 6047, CNPH 6244, CNPH 6400 Chata, CNPH 6400 Redonda, CPACT 1, CPACT 2, CPACT 3, Granex 429, Belém IPA 9, BRS Cascata, Crioula Alto Vale, Bola Precoce, Primavera, Régia, Valeouro IPA-11, Brisa and Alfa São Francisco. The evaluated characteristics were total soluble solid, titrate acidity, vitamin $C$ and pyruvic acid (pungency). The genotypes presented a significant variation for all the evaluated characteristics, confirming in such a way that the genetic factor is determinative in the characterization of each material. The total soluble solid varied from 6,67 to 11,63 ( ${ }^{\circ} \mathrm{Brix}$ ), vitamin $\mathrm{C}$ from 22,7 to 46.81 (mg acid ascórbico/ $100 \mathrm{ml}$ of juice) and the titrate acidity from 0,19 to 0.45 (\% of pyruvic acid). The genotypes presented intermediate pungency with variation of 5,0 the 12,73 ( $\mu \mathrm{mol} / \mathrm{g})$, being the least pungent Granex 429, CNPH 6047, Régia, Primavera e Belém IPA 9. Considering the group of the appraised characteristics, the genotypes BR Cascata, CNPH 6244, Belém IPA 9, IPA 11 and Primavera were the best in the conditions of Mossoró.

Index terms: Allium cepa, quality, pungency.

\section{(Recebido 22 de fevereiro de 2007 e aprovado 11 de setembro de 2007)}

\section{INTRODUÇÃO}

No Brasil, a cebola (Allium cepa L.) ocupa o terceiro lugar em importância econômica, com produtividade média de $17,88 \mathrm{tha}^{-1}$. A região Nordeste devido às condições edafoclimáticas, oferece grandes vantagens comparativas às demais regiões produtoras de cebola do país, uma vez que permite o plantio durante todo o ano. Os estados de Pernambuco e Bahia são os maiores produtores do Nordeste, respondendo por $99,0 \%$ da produção regional, que por sua vez correspondem a $18,2 \%$ da produção brasileira, com

\footnotetext{
'Engenheiro Agrônomo, Doutor em Produção Vegetal, Professor Adjunto II - Departamento de Ciências Vegetais/DCV - Universidade Federal Rural do Semi-Árido/UFERSA - Br 110, Km 47 - Costa e Silva - Cx. P. 137 - 59625-900 - Mossoró, RN - leilson@ufersa.edu.br

²Engenheiro Agrônomo, Doutor em Produção Vegetal - Faculdade de Ciência Agrárias e Veterinárias/FCAV - Universidade Estadual Paulista/UNESP Via de Acesso Professor Paulo Donato Castellane, s/n - 14884-900 - Jaboticabal, SP - jsoliveira1@hotmail.com

${ }^{3}$ Engenheira Agrônoma, Doutora em Pós-Colheita, Professora Adjunta I - Departamento de Agrotecnologia e Ciências Sociais/DACS - Universidade Federal Rural do Semi-Árido/UFERSA - Br 110, Km 47 - Costa e Silva - Cx. P. 137 - 59625-900 - Mossoró, RN - edna@ufersa.edu.br

${ }^{4}$ Engenheiro Agrônomo, Doutor, Professor Adjunto IIV - Departamento de Produção Vegetal/DPV - Universidade Federal Rural do Semi-Árido/UFERSA Br 110, Km 47 - Costa e Silva - Cx. P. 137 - 59625-900 - Mossoró, RN - glauber@ufersa.edu.br

${ }^{5}$ Engenheira Agrônoma, Doutora em Melhoramento Genético de Planta, Professora Adjunta I - Departamento de Agronomia - Universidade Federa Rural do Pernambuco/UFRPE - Unidade Acadêmica de Garanhuns/UAG - Avenida Bom Pastor, s/n - Boa Vista - 552996-901 - Garanhuns, PE g.mabel@uag.ufrpe.br
} 
produtividade média de 21,2 e 24,3 $\mathrm{t} \mathrm{ha}^{-1}$, respectivamente (IBGE, 2005).

Como ocorre com a maioria das hortaliças, a qualidade da cebola está intimamente ligada à aparência externa, ao tamanho do bulbo, cor, aroma, sabor, firmeza e composição química. Tais atributos são determinados, em parte, pelo genótipo, por tratamentos culturais na précolheita, pela época adequada de colheita e por tratamentos pós-colheita, que visam principalmente garantir a integridade física e manutenção da qualidade química dos bulbos (FINGER \& CASALI, 2002). Nas regiões produtoras, a maioria dos estudos com a cultura da cebola, abordam apenas os fatores ligados à produção, pouca ênfase tem se dado à qualidade do bulbo. Esses fatores, também são importantes na seleção da cultivar e aceitação pelo mercado consumidor, que é cada vez mais exigente.

Segundo Randle (1997) a composição química e as características sensoriais de sabor, cor e odor dependem mais do fator genético (cultivar) do que das condições de cultivo de solo, porém, a composição química do bulbo e a intensidade do sabor são também dependentes das condições do meio de desenvolvimento da planta, ao longo do seu ciclo vegetativo.

O tipo de cebola preferido varia com o mercado e a preferência do consumidor. No Brasil, há preferência por bulbos de tamanho médio, pungentes, globulares, firmes, de película externa de cor amarela e marrom escura, e escamas internas de cor branca. A demanda por bulbos avermelhados (arroxeados) é pequena e concentrada no Nordeste Brasileiro e na região de Belo Horizonte, em Minas Gerais. O mercado ainda é limitado para as cebolas de sabor suave e doce, preferidas para saladas (OLIVEIRA \& BOITEUX, 2006).

Há uma variabilidade grande entre as cultivares de cebola cultivada no Brasil, com relação ao rendimento, qualidade do bulbo e resposta ao fotoperíodo. Portanto, essa variabilidade existente permite que o cultivo de cebola possa ser feito praticamente em qualquer região, no entanto, devido à diversidade de climas e solos, o comportamento delas pode ser diferente, em função da região de plantio. Nesse contexto, no presente trabalho objetivou-se avaliar alguns atributos de qualidade de diferentes genótipos de cebola, cultivado em Mossoró-RN.

\section{MATERIAL E MÉTODOS}

O experimento foi conduzido no período de maio a setembro de 2004, na área experimental do Departamento de Ciências Vegetais da Universidade Federal Rural do Semi-Árido em Mossoró-RN, em solo classificado como
Argissolo Vermelho Amarelo. Da área experimental foram coletadas amostras de solos (0 - 0,3 m), cujos resultados das análises são apresentados a seguir. pH (água 1: 2,5) = 7,5; $\mathrm{Ca}=5,20 \mathrm{cmol} \mathrm{dm}^{-3} ; \mathrm{Mg}=0,60 \mathrm{cmol} \mathrm{dm}^{-3} ; \mathrm{K}=0,41$ $\mathrm{cmol}_{\mathrm{c}} \mathrm{dm}^{-3} ; \mathrm{Na}=0,08 \mathrm{cmol}_{\mathrm{c}} \mathrm{dm}^{-3} ; \mathrm{Al}=0,00 \mathrm{cmol}_{\mathrm{c}} \mathrm{dm}^{-3} \mathrm{e} \mathrm{P}=$ $146 \mathrm{mg} \mathrm{dm}^{-3}$.

$\mathrm{O}$ delineamento experimental utilizado foi em blocos casualizados completos, com 18 tratamentos e três repetições. Os tratamentos corresponderam aos genótipos de cebola CNPH 6415, CNPH 6047, CNPH 6244, CNPH 6400 chata, CNPH 6400 redonda, CPACT 1, CPACT 2, CPACT 3, Granex 429, Belém IPA 9, BRS Cascata, Crioula Alto Vale, Bola Precoce, Primavera, Régia, Valeouro IPA-11, Brisa e Alfa São Francisco. Cada unidade experimental foi composta por quatro fileiras de 50 plantas, espaçadas de $0,15 \mathrm{~m}$ entre linhas e $0,10 \mathrm{~m}$ entre plantas, com área total de $3 \mathrm{~m}^{2}$, por parcela.

O preparo do solo constou de uma aração a $0,30 \mathrm{~m}$ de profundidade, seguida de gradagem, e levantamento dos canteiros. As adubações foram realizadas com base na análise do solo e segundo recomendação de Cavalcanti (1998), sendo utilizado $45 \mathrm{~kg} \mathrm{ha}^{-1}$ de N, $45 \mathrm{~kg} \mathrm{ha}^{-1} \mathrm{de}_{2} \mathrm{O}_{5} \mathrm{e}$ $45 \mathrm{~kg} \mathrm{ha}^{-1} \mathrm{de}_{2} \mathrm{O}$, nas formas de uréia, superfosfato simples e cloreto de potássio respectivamente. Em adubação de cobertura foram utilizados $100 \mathrm{~kg} \mathrm{ha}^{-1}$ de $\mathrm{N}$ (uréia), parcelados em três aplicações (20, 35 e 50 dias após o transplantio) e $50 \mathrm{~kg} \mathrm{ha}^{-1}$ de $\mathrm{K}_{2} \mathrm{O}$ (Cloreto de potássio), parcelados em duas aplicações, aos 45 e 60 dias após o transplantio.

As mudas foram produzidas em sementeiras, com dimensões de $1 \mathrm{~m}$ de largura e 0,20 $\mathrm{m}$ de altura, cujo preparo consistiu de aração, gradagem e sulcamento. Utilizaram-se $10 \mathrm{~g} \mathrm{~m}^{-2}$ de sementes para semeadura em sulcos transversais ao comprimento do canteiro, com profundidade de $0,01 \mathrm{~m}$ e distância entre sulcos de $0,10 \mathrm{~m}$. O sistema de irrigação utilizado foi microaspersão, com freqüência diária e lâmina de irrigação de modo a manter sempre a capacidade de campo.

O transplantio foi realizado 39 dias após a semeadura (10/05/2004) quando as mudas atingiram 0,15 a $0,20 \mathrm{~m}$ de altura. Após o transplantio foi aplicado o herbicida oxadiazon na dose de $1 \mathrm{~kg} \mathrm{ha}^{-1}$ (i.a.), para controlar as plantas daninhas na fase inicial do ciclo da cultura, em seguida foram adotadas tratos culturais como capinas manuais e aplicações preventivas de defensivos para o controle de pragas e doenças com produtos registrados para a cultura.

A colheita foi realizada quando $80 \%$ das plantas se encontravam tombadas, o que dependeu do ciclo de maturação de cada genótipo. Após a colheita, os bulbos 
foram curados ao sol por período de seis dias, tendo-se sempre o cuidado de acomodar as plantas, de modo que a parte aérea de uma protegesse o bulbo da planta seguinte. Em seguida, procedeu-se o toalete eliminando-se o resto das raízes e parte aérea.

As seguintes características foram avaliadas após o processo de cura: sólidos solúveis totais (SST), vitamina C, acidez total titulável (ATT) e ácido pirúvico. Os sólidos solúveis totais, vitamina $\mathrm{C}$ e acidez total titulável foram determinados segundo metodologia preconizada pela AOAC (1992). O teor de ácido pirúvico foi determinado de acordo com metodologia de Schwimmer \& Weston (1961).

Os dados foram submetidos à análise de variâncias e as médias foram comparadas pelo teste de Scott-Knott, a $5 \%$ de probabilidade com o auxílio do programa Sisvar (FERREIRA, 2000).

\section{RESULTADOS E DISCUSSÃO}

Foram observadas diferenças significativas entre os genótipos para todas as características avaliadas. Para os teores de sólidos solúveis totais, houve uma variação de 6,67 a 11,63 'Brix, sendo que 'Granex 429' e 'Régia' apresentaram os menores valores (Tabela 1). Segundo Carvalho (1980) os valores dos sólidos solúveis totais em cebolas podem oscilar de 5 a $20 \%$, portanto os resultados encontrados no trabalho se encontram dentro dessa faixa. $\mathrm{O}$ alto teor de sólidos solúveis totais está ligado à alta pungência e à boa qualidade de armazenamento. Em cultivo orgânico no Vale do São Francisco, os teores de sólidos solúveis totais em cebola variaram de 5,25 a 11,72\%, com destaque para IPA 10 e IPA 11 que apresentaram os maiores valores (ARAÚJO et al., 2004). Em Minas Gerais, Chagas et al. (2004) observaram maiores valores de SST para as cultivares Crioula, Pira Ouro, Jubileu e Baia Periforme, com variações de 12,68 a 13,10\%.

Para a acidez total titulável os genótipos BRS Cascata, CNPH 6244 e Crioula Alto Vale, foram os que apresentaram os maiores valores, sendo respectivamente de 0,$45 ; 0,44$ e $0,43 \%$ (Tabela 1 ). A acidez juntamente com o teor de sólidos solúveis totais são parâmetros importantes responsáveis pelo sabor de frutas e hortaliças (CHITARRA, 1994). A acidez elevada é considerada desejável para a

Tabela 1 - Valores médios de sólidos solúveis totais (SST), acidez total titulável (ATT), vitamina C e ácido pirúvico de bulbos de 18 genótipos de cebola, avaliados em Mossoró-RN. UFERSA, 2004.

\begin{tabular}{lcccc}
\hline \multicolumn{1}{c}{ Genótipos } & $\begin{array}{c}\text { SST } \\
\left({ }^{\circ} \text { Brix }\right)\end{array}$ & $\begin{array}{c}\text { ATT } \\
(\% \text { de ácido pirúvico })\end{array}$ & $\begin{array}{c}\text { Vitamina C } \\
(\mathrm{mg} \text { ácid. ascórbico/100 ml de suco })\end{array}$ & $\begin{array}{c}\text { Ácido pirúvico } \\
\left(\mu \mathrm{molg}^{-1}\right)\end{array}$ \\
\hline Belém IPA 9 & $11,63 \mathrm{a}$ & $0,28 \mathrm{c}$ & $32,03 \mathrm{~d}$ & $6,70 \mathrm{c}$ \\
CNPH 6415 & $11,58 \mathrm{a}$ & $0,29 \mathrm{c}$ & $25,52 \mathrm{e}$ & $7,63 \mathrm{~b}$ \\
CNPACT 2 & $11,45 \mathrm{a}$ & $0,29 \mathrm{c}$ & $26,75 \mathrm{e}$ & $7,83 \mathrm{~b}$ \\
Crioula Alto Vale & $11,25 \mathrm{a}$ & $0,43 \mathrm{a}$ & $41,36 \mathrm{~b}$ & $9,03 \mathrm{a}$ \\
CNPACT 3 & $11,25 \mathrm{a}$ & $0,29 \mathrm{c}$ & $25,69 \mathrm{e}$ & $12,73 \mathrm{a}$ \\
CNPH 6400 Redonda & $11,10 \mathrm{a}$ & $0,29 \mathrm{c}$ & $24,29 \mathrm{e}$ & $7,90 \mathrm{~b}$ \\
CNPH 6244 & $10,84 \mathrm{a}$ & $0,44 \mathrm{a}$ & $4,86 \mathrm{~b}$ \\
BRS Cascata & $10,73 \mathrm{a}$ & $0,45 \mathrm{a}$ & $42,06 \mathrm{~b}$ & $8,80 \mathrm{~b}$ \\
CNPACT 1 & $10,65 \mathrm{a}$ & $0,30 \mathrm{c}$ & $46,81 \mathrm{a}$ & $7,43 \mathrm{~b}$ \\
IPA 11 & $10,61 \mathrm{a}$ & $0,35 \mathrm{~b}$ & $24,99 \mathrm{e}$ & $7,60 \mathrm{~b}$ \\
Bola Precoce & $10,55 \mathrm{a}$ & $0,38 \mathrm{~b}$ & $30,44 \mathrm{~d}$ & $7,56 \mathrm{~b}$ \\
Primavera & $9,33 \mathrm{a}$ & $0,37 \mathrm{~b}$ & $27,10 \mathrm{e}$ & $6,47 \mathrm{c}$ \\
Brisa & $9,29 \mathrm{~b}$ & $0,29 \mathrm{c}$ & $37,48 \mathrm{c}$ & $8,23 \mathrm{~b}$ \\
Alfa São Francisco & $9,17 \mathrm{~b}$ & $0,34 \mathrm{c}$ & $22,70 \mathrm{e}$ & $7,93 \mathrm{~b}$ \\
CNPH 6400 CHATA & $8,73 \mathrm{~b}$ & $0,36 \mathrm{~b}$ & $24,46 \mathrm{e}$ & $7,10 \mathrm{~b}$ \\
CNPH 6047 & $8,22 \mathrm{~b}$ & $0,32 \mathrm{c}$ & $29,21 \mathrm{~d}$ & $5,26 \mathrm{c}$ \\
Régia & $7,48 \mathrm{c}$ & $0,26 \mathrm{c}$ & $33,26 \mathrm{~d}$ & $5,76 \mathrm{c}$ \\
Granex 429 & $6,67 \mathrm{c}$ & $0,19 \mathrm{~d}$ & $24,46 \mathrm{e}$ & $5,00 \mathrm{c}$ \\
\hline CV(\%) & 6,67 & 8,73 & $23,76 \mathrm{e}$ & 15,33 \\
\hline
\end{tabular}

*Médias seguidas de mesma letra na coluna, não diferem estatisticamente pelo teste de Skott-Knott ao nível de 5\% de probabilidade. 
industrialização das cebolas, uma vez que expressa em porcentagem de ácido pirúvico, é um parâmetro utilizado para medir o grau de pungência (sabor e aroma). Os bulbos de cebola que apresentarem esses teores elevados são considerados de melhores qualidades para a desidratação, em que partes desses compostos aromatizantes são perdidos durante esse processo (CHAGAS et al., 2004).

Quanto aos teores de vitamina C, os valores situaram-se na faixa de 22,70 a 46,81 mg ácido ascórbico/ $100 \mathrm{ml}$ de suco, com o genótipo BRS Cascata, sobressaindo-se dos demais, apresentando o maior valor. Esses valores foram superiores aos teores apresentados por Bertolucci et al. (2002) que é de 9,7 mg/100g de polpa. A divergência nos teores de vitamina $\mathrm{C}$ pode ser atribuída à metodologia adotada entre os trabalhos.

Para os teores de ácido pirúvico, a variação foi de 5,0 a $12,73 \mu \mathrm{molg}^{-1}$, e os genótipos Crioula Alto Vale e CNPACT 3 apresentaram os maiores valores, não diferindo entre si, e os menores 'Granex 429', 'Régia', 'CNPH 6047', 'Primavera' e 'Belém IPA 9'. Em avaliação realizada por Shunemann et al. (2006) no Alto Vale do Jataí - SC, com os mesmos genótipos, o teor de ácido pirúvico variou de 4,84 a 7,61 $\mu \mathrm{molg}^{-1}$ com o genótipo CNPH 6047 apresentando maior valor, embora não tenha diferido significativamente de 'CNPH6040', 'CNPH 6415', 'CNPH 6244', 'BRS Cascata', 'Primavera' $x$ 'Pera Norte' (CNPACT 2), 'Texas Grano 1015 Y', 'Pêra Norte' $x$ 'Primavera' (CNPACT 1), 'CNPH 6400 redonda,' 'Crioula Alto Vale' e 'Primavera'. O genótipo Granex 429 apresentou menor teor, nos dois locais de avaliação. No Vale do São Francisco, Ramos et al. (2005) não verificaram diferença significativa entre as cultivares avaliadas, porém os valores obtidos (4,61 a 5,53 $\left.\mu \mathrm{molml}^{-1}\right)$ foram também inferiores aos do presente trabalho. No sul de Minas Gerais, as cultivares Crioula $\left(6,66 \mu \mathrm{molg}^{-1}\right)$ e Baia Periforme $\left(5,93 \mu\right.$ molg $\left.^{-1}\right)$ destacaram-se das demais (CHAGAS et al., 2004). Considerando a classificação da pungência de cebola proposta por Schwirmmer \& Weston (1961), medida em função da quantidade de ácido pirúvico, como cebola fraca (2 a $4 \mu \mathrm{molg}^{-1}$ ), intermediária (8 a 10 $\left.\mu \mathrm{molg}^{-1}\right)$ e forte $\left(15\right.$ a $\left.20 \mu \mathrm{molg}^{-1}\right)$, os genótipos foram classificados como intermediários.

Percebe-se, portanto, que os teores de ácido pirúvico e a pungência da cebola, observados no presente trabalho foram, de uma forma geral, superiores aos obtidos nos experimentos conduzidos em outras regiões, mesmo naquelas onde as cultivares de cebola foram comuns. Embora a pungência em cebola, seja influenciada por diversos fatores, as temperaturas mais elevadas verificadas em Mossoró parece ter sido o fator principal, que corroborou para maior pungência em relação às demais regiões.
Segundo Randle (1997), a intensidade da pungência é governada por fatores genéticos e as condições ambientais em que a mesma é cultivada, principalmente, os teores de enxofre do solo, temperatura e disponibilidade de água. Em locais com teores de enxofre do solo alto e/ou adubação excessiva com esse nutriente (LANCASTER et al., 2000), há uma tendência de maiores pungência da cebola, o mesmo acontecendo quando a cebola é cultivada em altas temperaturas ou sobre estresse hídrico. Por outro lado, Sun Yoo et al. (2006) estudando o efeito dos fatores genéticos e ambientais na pungência de cebola, verificaram que $81,3 \%$ da variação da pungência foi determinada pelo fator genético, e o ambiente influenciou em menor grau.

\section{CONCLUSÕES}

Os genótipos apresentaram uma variação significativa para todas as características avaliadas, confirmando dessa forma que o fator genético é determinante na caracterização de cada material;

O teor de sólidos solúveis totais variou de 6,67 a 11,63 ( ${ }^{\circ}$ Brix), vitamina C de 22,7 a 46,81 (mg ácido ascórbico/100 $\mathrm{ml}$ de suco) e a acidez total titulável de 0,19 a 0,45 (\% de ácido pirúvico);

Os genótipos apresentaram pungência intermediária com variação de 5,0 a 12,73 ( $\mu \mathrm{mol} / \mathrm{g})$, sendo os menos pungentes 'Granex 429', 'CNPH 6047', 'Régia', 'Primavera' e 'Belém IPA9';

Considerando o conjunto das características avaliadas, os genótipos BR Cascata, CNPH 6244, Belém IPA 9, IPA 11 e Primavera, apresentaram melhor comportamento nas condições de Mossoró.

\section{REFERÊNCIAS BIBLIOGRÁFICAS}

ARAÚJO, J. F.; COSTA, N. D.; LIMA, M. A. C.; PEDREIRA, C. M.; SANTOS, C.; LEITE, W. M. Avaliação de genótipos em cultivo orgânico. Horticultura Brasileira, Brasília, v. 22, n. 2, jul. 2004. Suplemento.

ASSOCIATION OF OFFICIAL AGRICULTURAL CHEMISTS. Official methods of analysis of the Association of the Agricultural Chemistry. 11. ed. Washington, DC, 1992. $1115 \mathrm{p}$.

BERTOLUCCI, S. K. V.; PINHEIRO, R. C.; PINTO, J. E. B. P.; SOUZA, R. J. Qualidade e valor nutracêutico da cebola. Informe Agropecuário, Belo Horizonte, v. 23, n. 218, p. 8892, 2002. 
CARVALHO, V. D. Características nutricionais, industriais e terapêuticas da cebola. Informe Agropecuário, Belo Horizonte, v. 6, n. 62, p. 71-78, 1980.

CAVALCANTI, F. J. A. Recomendação de adubação para o estado de Pernambuco: 2a aproximação. Recife: IPA, 1998. p. 127.

CHAGAS, S. J. R.; RESENDE, M. R.; PEREIRA, L. V. Características qualitativas de cultivares de cebola no Sul de Minas Gerais. Ciências e Agrotecnologia, Lavras, v. 28, n. 1, p. 102-106, 2004.

CHITARRA, M. I. F. Colheita e pós-colheita de frutos. Informe Agropecuário, Belo Horizonte, v. 17, n. 179, 1994.

FERREIRA, D. F. Sistemas de análises estatística 3.1. Lavras: FAEPE/UFLA/PEX, 2000.

FINGER, F. L.; CASALI, V. W. D. Colheita, cura e armazenamento de cebola. Informe Agropecuário, Belo Horizonte, v. 23, n. 218, p. 93-98, 2002.

INSTITUTO BRASILEIRO DE GEOGRAFIA E ESTATÍSTICA. Censo agropecuário. Disponível em: $\langle$ http://www.agricultura.gov.brr〉. Acesso em: 18 maio 2005.

LANCASTER, J. E.; FARRANT, J. F.; SHAW, M. L. Effect of sulfur supply on alliinase, the flavor generating enzyme in onions. Joumal of Food Biochemistry, Amsterdam, v. 24, p. 353-361, 2000.
OLIVEIRA, V. R.; BOITEUX, L. S. Cultivo da cebola. Disponível em: $K$ http://WwW.cnph.embrapa.br/paginast isistemas =producao/cultivo_da_cebola.htm 10 nov. 2006.

RAMOS, P. S. R.; DEON, J. S. dos; ARAGÃO, C. A. Desempenho e pungência de genótipos de cebola na região do Submédio São Francisco. Horticultura Brasileira, Brasília, v. 23, n. 2, 2005. Suplemento.

RANDLE, W. M. Onion flavor chemistry and factors influencing flavor intensity. ACM Symposium Series, [S.1.], v. 660, p. 41-42, 1997.

SCHWIRMMER, S.; WESTON, W. J. Enzimatic development of pyruvic acid as a measure of pungency. Journal Agricultural Food Chemistry, Easton, v. 9, p. 301304, 1961 .

SHUNEMANN, A. P.; TREPTOW, R.; LEITE, L. D.; VENDRUSCOLO, J. L. Pungência e características químicas em bulbos de genótipos de cebola (Allium cepa L.) cultivados no alto Vale do Itajaí, SC, Brasil. Revista Brasileira de Agrociência, Pelotas, v. 12, n. 1, p. 77-80, 2006.

SUN YOO, K.; PIKE, L.; CROSBY, K.; JONES, R.; LESKOVAR, D. Differences in onion pungency due to cultivars, growth environment, and bulb sizes. Scientia Horticulturae, Amsterdam, v. 110, p. 144-149, 2006. 